\title{
An Integrative Approach to Curriculum Development in Higher Education in the USA: A Theoretical Framework
}

\author{
Mohammad Ayub Khan ${ }^{1} \&$ Laurie Smith Law $^{2}$ \\ ${ }^{1}$ Tecnologico de Monterrey, Mexico \\ ${ }^{2}$ University Honors Program, Iowa State University, USA \\ Correspondence: Mohammad Ayub Khan, Tecnologico de Monterrey, Campus Monterrey, NL, Mexico. E-mail: \\ mkhan@itesm.mx
}

Received: August 8, $2014 \quad$ Accepted: December 2, $2014 \quad$ Online Published: February 25, 2015
doi:10.5539/ies.v8n3p66

\begin{abstract}
The role of curriculum in higher education is sine quo non for the provision of quality and relevant educational programs and services to the current and potential learners in the USA and elsewhere in the world. Regardless of sizes, types or origins, curriculum is considered the heart and soul of all educational institutions. Curriculum is crucial for the well-being and effectiveness of higher education (Barnett \& Coate, 2005) both in the short and long-term. Lamentably, it is a widely recognized notion in academia that the approach to developing curriculum is disintegrated in that minimal and isolated considerations are given to the various critical elements such as institutional leadership, social trends, industry factor and the role of the government. Therefore, this paper is dedicated to the study of existing literature on an integrative approach to curriculum development as a source of relevant, timely and comprehensive knowledge management in institutions of higher education with a particular reference to the USA.
\end{abstract}

Keywords: curriculum development, education environment, educational leadership, graduate competencies, pedagogy

\section{Introduction}

Whether privately or state run developing curriculum is culturally and nationally bound in that different nations have different policies, programs and institutions involved in guiding and supervising curriculum development. In the existing literature on curriculum development in countries like Australia, UK and the USA, the degree and type of government incursion into the domain of higher education management varies from country to country. Regardless of the government involvement higher education institutions are expected to make sure that "The curriculum is clear about what has to be taught and what should be learned at each stage of schooling, is based on reasonable expectations of time and resources, and is flexible and developed collaboratively with schools and jurisdictions (Australian Curriculum, Assessment and Reporting Authority, 2010a)." Curriculum is the foundation of the teaching-learning process. It involves developing programs of study (study plans), teaching strategies, resources allocations, specific lesson plans and assessment of students, and faculty development (Alberta Education, 2012). Given these realities the approach to developing curriculum in higher education institutions is and should be a prime concern for all stakeholders, especially for educators, policy-makers, government, parents and the society at large (Alberta Education, 2012; De Coninck, 2008).

Educational institutions and employers alike are of the view that education should help students gain knowledge and basic skills (Bounds, 2009). Designing appropriate curriculum is crucial for providing such knowledge and skills. Moreover, there is a growing need for higher education institutions to respond to the changing environment in a positive and learner-centered manner through quality curriculum. For example, the competence-based curriculum produces graduates who are better prepared for their future management tasks. Students who have learned to adapt to change and to adapt their abilities to a variety of contexts and situations, develop managerial competencies for a turbulent world (Pacheco, 2000, cited in Bounds, 2009). Interestingly the theory and practice of curriculum development in educational institutions have remained and continue to be hotly debated themes in academia, mainly because there are different definitions and interpretations of the term curriculum in addition to variations in approaches to curriculum design. Most importantly, the terms "curriculum" and "education" though defined and interpreted differently in theory, nonetheless, are interrelated 
and inseparable in practice. Therefore, designing an appropriate curriculum is considered (as) a foundation stone for high quality programs and services, regardless of the type of educational programs and institution. Integral education is about developing a whole person, so the approach to curriculum management (designing, implementing, assessing) should encompass both technical skills and the development of the learner as a whole person (Fish, 2013).

Curriculum is critical in providing high quality educational programs and services; however, there are gaps between how curriculum is developed and how curriculum is supposed to be developed in theory. This dilemma is further complicated by the fact that there are huge differences between the curriculum published by the educational institutions and the curriculum actually taught by the teachers in their classrooms. Curriculum is considered as a foundation stone for the "well-being and effectiveness of higher education" (Barnett \& Coate, 2005 , p. 7). Regardless of how curriculum is defined and what are its scope and importance, it is one of the most significant matters in higher education; however, little attention has been given to the evolution of curriculum, its review and transformation in the institutions of higher education (Hyun, 2006, 2009). This notion is further strengthened by the fact that there is dearth of research works on the subject and the literature that exists is mostly focused on the design of the curriculum (Hicks, 2007).

Developing an integrative curriculum has become a globally discussed issue and challenging for all institutions of higher education. In this paper a literature review based exploratory analysis is undertaken in order to find an integrative approach to curriculum development in the context of the USA. Furthermore, this paper provides a theoretical-conceptual framework which could be used for defining the process of curriculum management (development, implementation and evaluation) by all stakeholders in the educational institutions, whether they are located in the USA or elsewhere in the world.

\section{Literature Review}

Curriculum development is a process which goes through different stages and is undertaken after every specified period defined by an educational institution concerned. Though it may vary from university to university, generally it is a five years period with ongoing revision and updates. Developing curriculum may take more or less 3 months depending on the size of the institution. Once curriculum is developed, its implementation and evaluation are spread across the specified five years. An approach to develop curriculum therefore, should encompass design, implementation and assessment. Ornstein and Hunkins (2009, p. 15), suggest that "Curriculum development encompasses how a curriculum is planned, implemented and evaluated, as well as what people, processes and procedures are involved." Having a road-map in the form of a curriculum model may help curriculum development leaders to systematically and comprehensively approach this challenging and complex task (O’Neill, 2010).

In order to understand and evaluate the existing theories of curriculum development in institutions of higher education with a particular reference to the USA, a thorough literature review is carried out with a focus on issues presented in Figure 1 as a conceptual framework of the study. Figure 1, demonstrates that while developing curriculum, which is the main focus of this paper, all institutions of higher education regardless of their types, origins and sizes should consider: Environmental variables surrounding the institution; pedagogical strategies to be used to implement the learning and teaching activities envisaged in the curriculum; graduate competences to be developed; and, educational institution leadership that is required. 


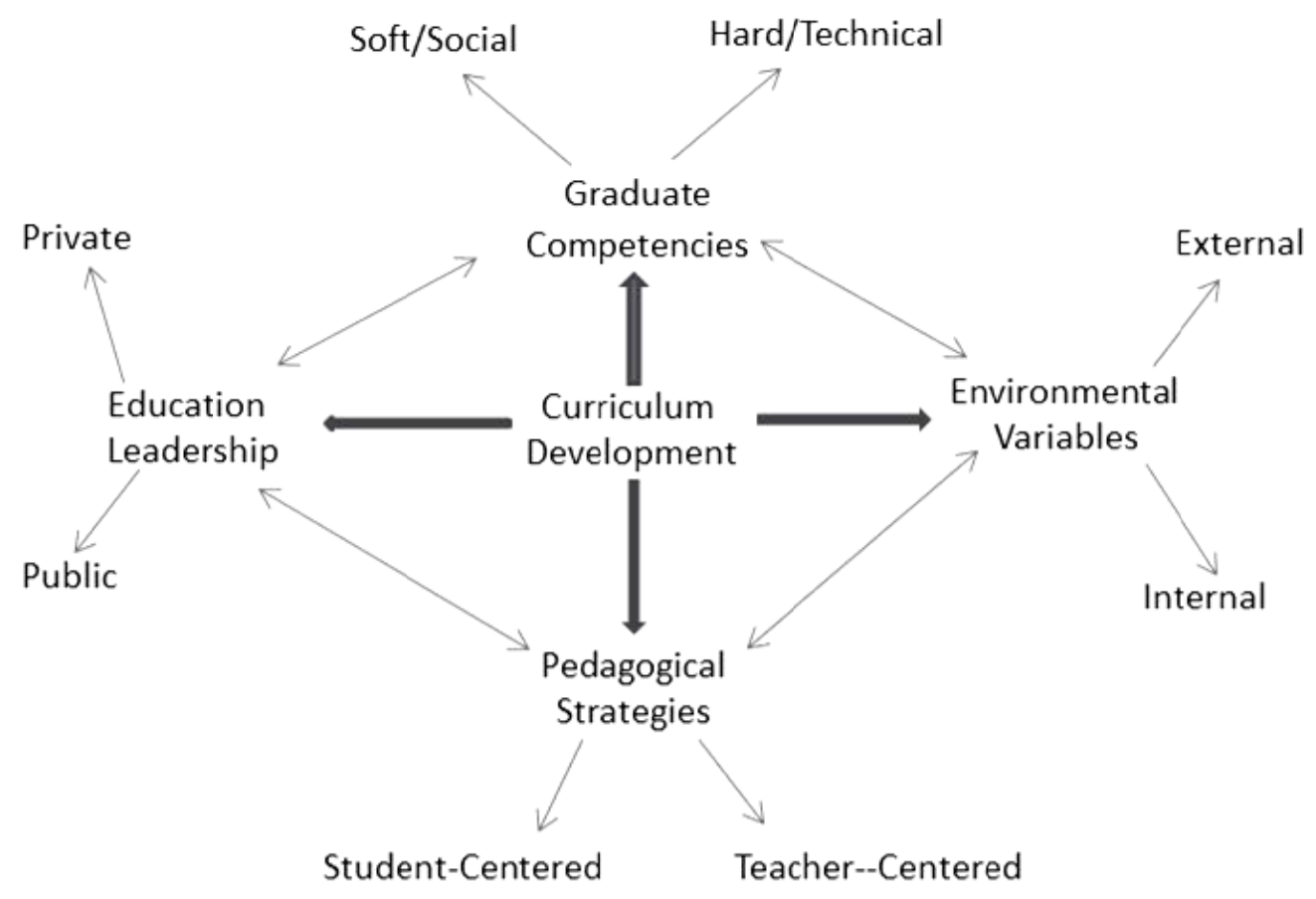

Figure 1. An Integrative approach to curriculum development

\subsection{Curriculum Development}

According to different sources available in the existing literature (Egan, 2003), the term curriculum has its origins in the running/chariot tracks of Greece (literally meaning a course). In Latin curriculum is a racing chariot and the word currere is meaning to run. Curriculum is about all the learning activities that are carefully planned and guided by the education institution involved and carried out by learners in groups or individually, in-classroom or off-classroom context (Mednick, 2006). As runners need a carefully crafted plan and guidance in advance, learning should be planned and guided in order to specify the target and methods to reach the desired learning outcomes. Curriculum is about defining or proposing which courses or subjects should be taken by students of a particular academic program, professors preparing their assigned courses or subjects before the start of each semester, as well as providing learning outcomes that have a positive impact on the students (Null, 2011) In designing curriculum, designers should consider objectives, as well as methods, materials, and assessment procedures and system. These guidelines apply to the general education curriculum which, when universally designed, should meet the educational needs of most students, including those with disabilities (Njogu, 2012). Educational theorists (Mednick, 2006; González, Quesada, J. Mueller, \& R. Mueller, 2011) view curriculum as a broader concept and therefore, is characterized as: a body of knowledge or product; a process; praxis (practice); and a context. Since, quality education is not only about building certain pre-determined skills, but it is also about the realization of one's full potential and the ability to use those skills for the greater good of self and others (Dewey, 1918, 1966; Miller \& Seller, 1985), the task of curriculum development demands a comprehensive approach.

Going back to the history of debates on curriculum development, Tyler (1969), suggested following these essential elements in order to design a successful curriculum: Educational purposes of the institutions; availability of the educational experiences to attain these purposes; organization of educational experiences; mechanisms to measure whether these purposes are being attained. The curriculum development approaches proposed by Tyler (1950) and Taba (1962) greatly influenced and guided the way curriculum development was undertaken for several years. Though considered traditional and narrowly focused but still useful and appreciated these curriculum development models were composed of the same basic elements used in the contemporary models of curriculum development such as: define the goals (purposes or objectives); define experiences or activities related to the goals; organize the activities or experiences; and, finally, evaluating the goals. Given the current global dynamics and multidimensional challenges face by our societies some experts in the field of education recommend that curriculum should envisage broader goals and learning objectives of the educational 
institutions involving social, cultural, political, and religious values of a society (Krull \& Kurm, 1996). The scope of the term curriculum is reflected in different names given to it as described below (Cuban, 1992; Cortes, 1981; Longstreet \& Shane, 1993) showing the degree of importance of curriculum for the educational programs and educational institutions:

- Official curriculum (curriculum approved and published by the concerned education institution in terms of the programs of study like courses, and contents etc.).

- Taught curriculum (what is actually taught in classroom by the teachers).

- $\quad$ Learned curriculum (what is actually learned by the learners).

- Tested curriculum (what is actually measured by the education institution through different testing mechanisms).

- The hidden or covert curriculum (i.e., students learn from examples and behavior demonstrated by a teacher like punctuality, respect, and discipline).

- The null curriculum (i.e., some aspects of the curriculum are not taught intentionally or unintentionally).

Figure 2 below provides a comprehensive approach to curriculum development involving co-curricular and core-curricular teaching and learning activities. Core curricular activities tend focus on a particular discipline (concepts, theories etc.) whereas co-curricular activities are assumed to include themes of sports, music, dance, and culture etc. An appropriate combination of these two key elements of quality-cum-inclusive educational programs and services is believed to help produce graduates with balanced competencies (hard skills and soft skills) desired in the intellectual-professional market of the globalized world.

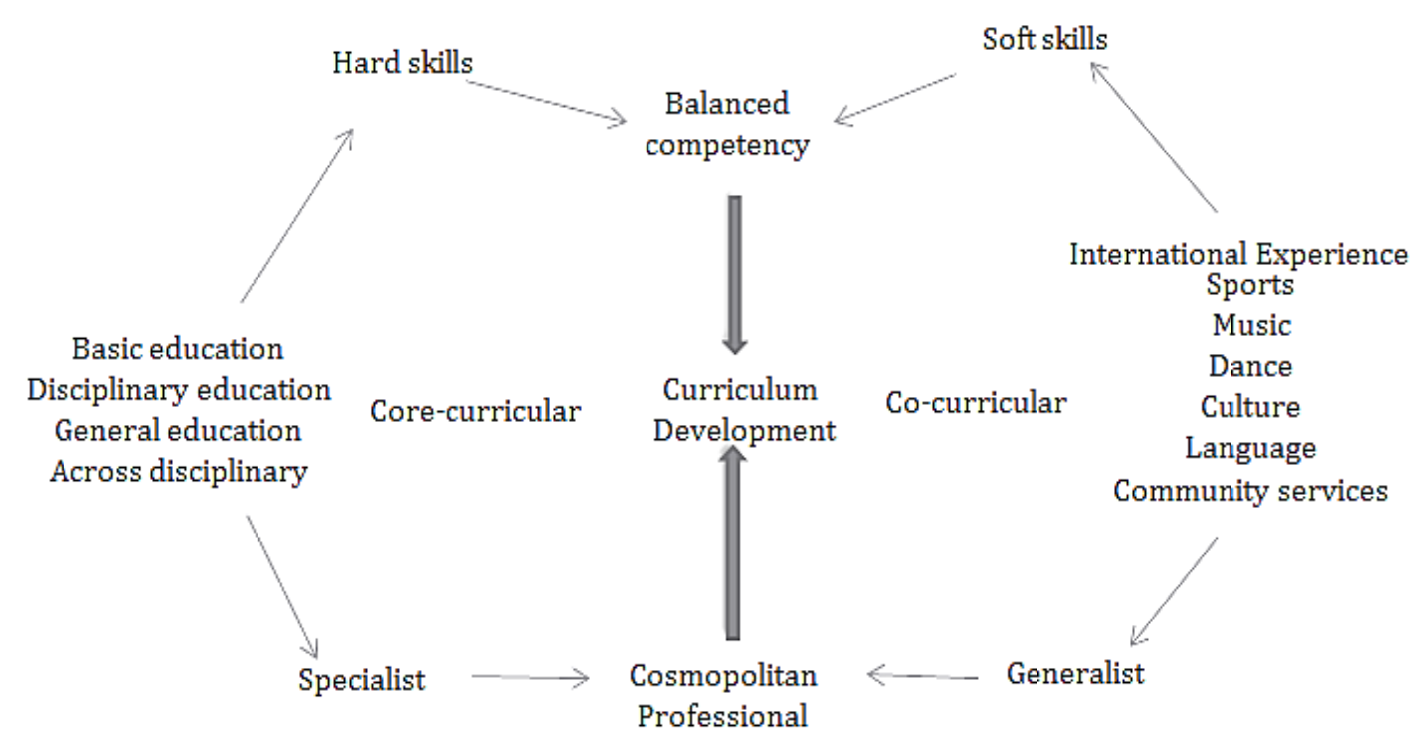

Figure 2. Curriculum dimensions

\subsection{The Environmental Analysis}

The educational environment can be viewed from two different perspectives: the internal environment and the external environment. The internal environment which is also called the institutional environment reflects the culture, operations, people, strategies and structures of the institution. The history, customs and traditions, and work routines developed and maintained over a long period of time also make up the internal environment or organizational culture. How decisions are made and if employees (teachers and administrative staff) are involved in managerial and policy related decisions-making such as curriculum development are parts of the internal environment. On the other hand, the external environment of the institution is classified into two: the education sector or industry and the general or macro environment. At the educational or industry level, the analysis includes: the existing number of institutions of higher education functioning in the sector; the rate of entry of 
new educational institutions into the education sector; how frequently new academic programs (both at graduate and undergraduate levels) are changed and offered; establishing new academic standards; and, introducing new educational models (such as Online and Virtual educational programs). At the university or institutional level, the analysis includes: the degree of collaboration versus competition among different schools inside the university; changes in structure and strategies, the level of institutional support for new program innovation; introduction of new educational models; and, establishing new academic standards so and so forth.

The general or macro environment surrounding educational institutions has seen drastic and novel changes. The causes of these changes include (Hallinger \& Snidvongs, 2008): the emergence of global market which is more connected and integrated; an open and free economic system; an investment friendly and democratic political system; and, the revolutionary changes in the field of information and communication technologies. Sibley (1998) identified several emerging issues that coincide with the challenges facing today's institutions of higher education around the world: increasing global competition; a knowledge age workforce requiring critical thinking skills, flexibility and cooperation; and life-long learning and second career training. Developing and graduating students with diverse competencies such as critical thinking, coping, creativity, problem solving silks and normative/applied ethics is the responsibility of all educational systems (Sibley, 1998). It is believed that education institutions develop and transfer knowledge and prepare graduates for the real world (the workplace). Thus, they influence successful industry-work related practices and public policies (Li, Wong, \& Wang, 2005). In response, educational institutions of higher education have to make significant adaptations in the curriculum designed for the current as well as the future learners.

\subsection{Pedagogical Strategies}

Pedagogy as a term is defined as a teaching method, a way of doing something, especially a systematic way, implies an orderly logical arrangement or "the function or work of a teacher or teaching". It is also the art and science of teaching (Webster's College Dictionary, 2010). Cogill (2000) defines pedagogy as being any activity in which both learner and teacher actively participate and thus, suggesting that pedagogy is also about the social interaction between teachers and students. Pedagogy encompasses both teaching and learning methods. In this paper pedagogical methods are divided into two broad categories: Informal or less systematic methods; and, formal or more systematic methods. The informal or less systematic methods include:

- Open classroom discussion.

- Report writing.

- Verbal presentations.

- Lecturing.

- Brain storming.

- Role play.

- Question and answers (Q\&A).

- Memory based learning.

- Observations.

- $\quad$ Field visit and study tours.

- Social meeting/gathering.

- Interviews.

The formal and more systematic methods include:

- Case based learning (students are asked to analyze (reading and discussing) real life complex situations (cases or scenarios).

- Collaborative learning (students are asked to collect information about a certain subject or emerging issue in the field of study and share that information with each other in the class or out of class).

- Project based learning (students are asked to design a product prototype, a service or building). Of course, students are expected and required to collect enough information before they start working on the project.

- Problem oriented learning (students are assigned specific real life problems to solve).

- Service based learning (students learn from being involved in community services; internship programs, and other social welfare programs). 
- $\quad$ Research based learning (students are asked to carry out formal research on a specific topic or subject assigned by the teacher. Research work consists of designing a research proposal, research development, results presentation and publication).

A course should be designed and taught using any one or combination of these methods. Training and evaluation of the teacher is the key to successfully adapting these methods in the classroom. The support of pedagogical experts is necessary in designing and training the faculty. Students' orientation is also important in implementing such methods. Other teaching and learning mechanisms such as professional practices (company based internships) can also add value to the knowledge and experience of the students. Complementary educational programs including co-curricular activities (or transversal programs) such as sports, music and dance help students build abilities (communication, discipline, self-confidence) and social networks. Designing multidisciplinary concentrations (or minors) and modalities are helpful in allowing students to specialize in their area of interest (i.e., research, innovation, consulting, entrepreneurship, and social leadership development). Furthermore, pedagogy can be well supplemented by sending students abroad, for a period of one semester to a year or at least for a summer, allowing them to learn from living and study in an international environment. International exposure allows students to learn about new cultures, meet people from different cultural backgrounds, network and develop more broad-minded views. These are critical skills university graduates are expected to and should possess in order to function successfully in the emerging global market-workplace.

Though there are different pedagogical methods available for educational institutions, the application or implementation of those methods depends on the educational approach to teaching: student versus teacher centered. Experts suggest teaching goals, organization of curriculum, course structure and pedagogy must be student centered (Huba \& Freed, 2000). In short, pedagogy must be dynamic, diverse, challenging and interesting. It is also important for students' learning styles (active versus passive) and teaching styles (student versus teacher centered) be taken into considerations and students be at the center of the education policies and programs.

\subsection{Graduate Competencies}

The term competency refers to knowledge, skill, or attitude that enables one to effectively perform the activities of a given occupation or function to the standards expected in employment (International Board of Standards for Training and Performance Instruction, 2005). Competency is the combination of skills, abilities, and knowledge needed to perform a specific task (The National Center for Education Statistics (NCES) of the U.S. Department of Education, 2002). In business and professional life, competencies are used for employee selection, the basis for compensation, performance measurement, training needs assessment, training outcomes assessment, and strategic planning. It is believed that having knowledge alone is not sufficient in today's society; students need to adapt to change and to apply their knowledge to solving problems (Evers, Rush, \& Berdrow, 1998). Four common competencies are found in the existing literature: managing self; communicating; managing people and tasks; and, managing innovation and change (Evers et al. 1998). Other competencies include: critical thinking, interpersonal skills and computer skills. Overall, the purpose is to develop professional behaviors in learners which may include time management skills, making ethical decisions, participating in professional organizations, appropriate professional appearance, and appropriate meeting behaviors (Hall, 2006). For example, important technical skills needed for a job in business are: production and operations management, human resources management and strategic planning (Fr. David \& Fo. David, 2011). The generic competencies important for the business students to possess once they graduate are: ethical reasoning, language and communications abilities, problem-solving skills, and preparation for lifelong learning (AACSB International, 2012). AACSB is the Association to Advance Collegiate School of Business. It is a USA based organization but has international branches. It deals with accreditation and standards for business and accounting programs.

In summary, considering the continuing change of social, cultural and organizational contexts, this new postmodern atmosphere requires professionals to develop lifelong learning competencies. Mastery of an academic profession requires that students acquire at least three important competencies regardless of any particular discipline or field of study (Nygaard, Hojlt, \& Hermansen, 2006): Competent use of models and theories (theoretical understanding); competent use of research methods (analysis, structuring ideas); and, competent analysis of empirical practice (application and practice).

\subsection{Education Institutional Leadership}

Conducive, dynamic and supportive leadership is vital in the process of developing, implementing and evaluating curriculum. The phrase 'lead, follow, or get out of the way' is meaningful in the management and long term direction of these institutions. There is a time to lead, a time to follow and a time to get out of the way 
(Sibley, 1998). At the school/college level, the dean, associate dean, department chairs, and team captains constitute the leadership team. Team structure is beneficial for educational institutions and must be adopted for several reasons: (a) involves individuals with several skills and functions who can synergistically perform major organizational tasks; (b) offers the capability to break down barriers among departments, which can enable the coordination necessary to obtain desired services; (c) provides access to resources such as information, equipment, and supplies necessary to perform assigned tasks; and, (d) empowers its members with decision-making authority. Faculty participation is essential because the teams themselves, rather than the organizational leaders, take responsibility for, decisions, monitor their own performance, work toward goal attainment, and adapt to environmental changes (Wageman, 1997). Educational leaders need to: articulate a vision and create the structure for that vision to come to fruition, not just in words but also in actions; be symbols of the institutional values that they lead and lead with moral courage and purpose in support of all institutions of higher education; be cognizant of the symbolic nature of their position when taking action; be role models for students, faculty, and other academic institutions; teach lessons by what they support and how they act; and be conscious of the possible implications of their decisions and actions, for surely everyone is watching-especially the students. The roles of the educational leader are many: coach, teacher, counselor, facilitator, director, and sometimes parent (Pfeffer, 2009; Quick \& Normore, 2004). As an educational leader, one must be willing to serve and to subordinate oneself to the vision and best interests of the organization. The new view of leadership in learning organizations centers on subtler and more important tasks. In a learning organization, leaders are designers, stewards, and teachers. They are responsible for building organizations where people continually expand their capabilities to understand complexity, clarify vision, and improve shared mental models-that is, they are responsible for learning (Quick \& Normore, 2004).

In summary, educational institutions, regardless of their size (big or small), types (private or public) and nature of educational programs (business, medicine, engineering, social sciences etc.), require leadership which is not traditional and theoretical, rather dynamic, pragmatic, participative, strategic, and most importantly, future oriented, socially inclusive and maintains high ethical standards.

\subsection{An Integrative Approach to Curriculum Development}

Curriculum development is a process and system as well as a science and art. A carefully crafted process and efficient system involving all influential variables is the only option in the contemporary world of education which is unpredictable and highly competitive. Curriculum development should be central focus of the strategic planning activity of an institution. Figure 3 shows that curriculum development requires a systematic approach and therefore, should be approached in stages. In stage 1, both internal and external environment should be studied in order to have a comprehensive knowledge and understanding of what is happening in and around the educational institutions. In stage 2, which is more closely related to and is based on the knowledge of stage 1, specific competencies to be developed in students are identified and analyzed. These competencies are then classified into personal, professional and institutional competencies. In stage 3, the actual curriculum is designed and developed keeping in mind the knowledge of previous two stages. In stage 4, specific pedagogical strategies, which are most relevant and effective in imparting the knowledge intended in the curriculum are identified and proposed. In stage 5, it is critical for educational institutions to establish necessary mechanisms to: follow-up the implementation of curriculum as planned; carry out regular evaluation of the learning outcomes; and, provide necessary and on time feedback to interested parties in education including policy makers, academic directors, parents, teachers and students a few to name (to name a few). Figure 3 also suggests that while developing curriculum other factors such as society, industry, and the role of government have to be fully taken into account. This requires dynamic, participative and pro-active institutional leadership. 


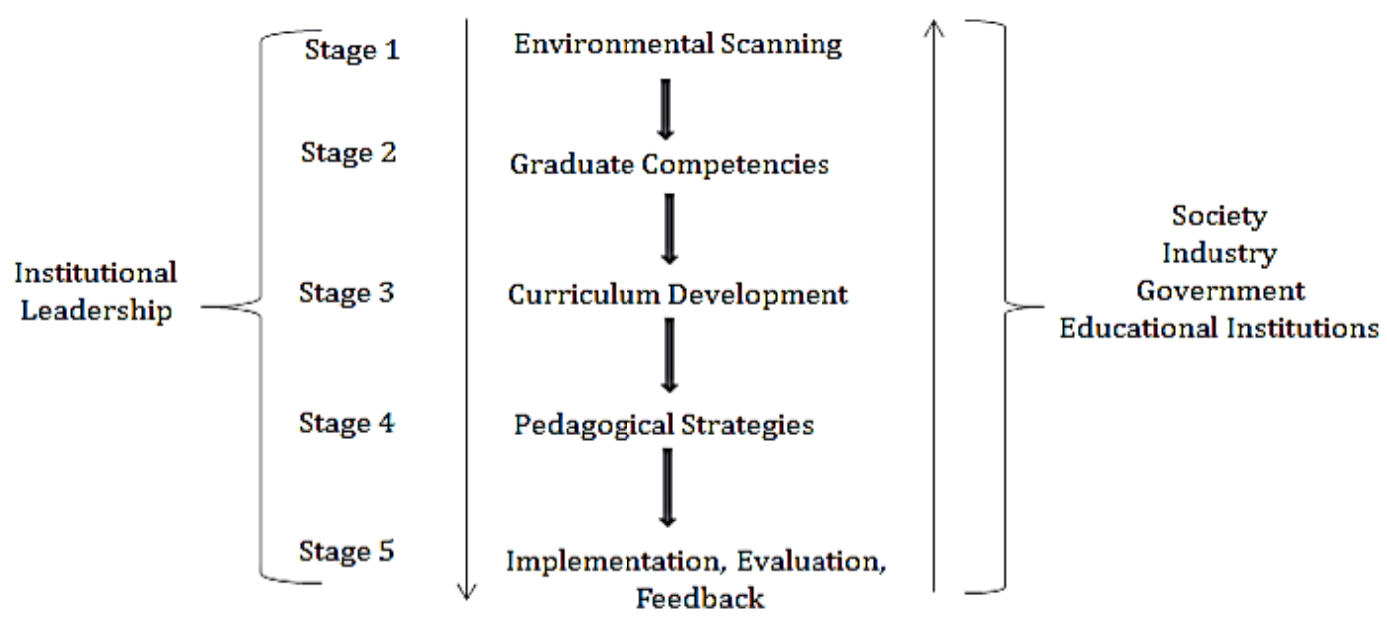

Figure 3. Curriculum development process \& system

Figure 4, further envisages that the educational life of a learner is not a cycle, rather a unidirectional and a straight forward pathway. There is no option of going back to stage one or two once a learner moves forward (from one level to another). Moreover, individual background and personality factors such as demographics (i.e., age, income, marital status) and psychographics (i.e., interests, opinions, life style, needs, self-efficacy) are constantly and gradually changing with the passage of time-let alone the social dynamics of human life. Additionally, while designing curriculum, connecting-past, present and future-the knowledge and experience of learners will definitely make the curriculum more learner oriented, interesting and innovative. This is also helpful in making the learning environment and teaching activities more relevant and well-grounded for learners.

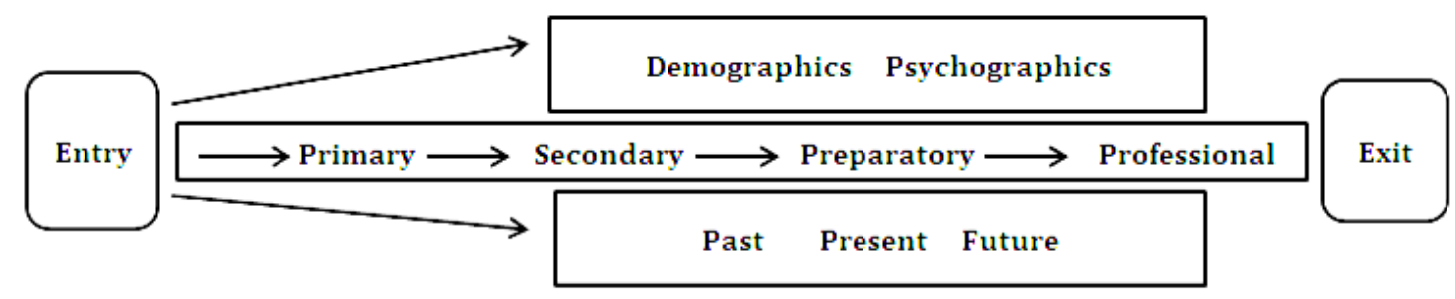

Figure 4. Education life direction

\section{Conclusions \& Implications}

Interestingly, but not surprisingly, the discussion on the importance of curriculum development in educational institutions is historical and as well contemporary and the debate will continue during the twenty first century (Bounds, 2009). Curriculum development costs money, is risky as a strategy, time consuming, but the direct and indirect benefits derived from it are far higher for all current and potential beneficiaries. Developing education curriculum is not an easy task, especially, in the current global and changing work environment. For some institutions it could be as simple as adding a few new courses or changing a few topics in the existing curriculum which is done by few academic administrators. But in other educational institutions, curriculum development is given institutional support by associating-linking it with the mission and vision of the institution. The exercise of curriculum development should be highly inclusive, participative and democratic (involving all interested stakeholders). Overall, developing an integrative curriculum is beneficial for any educational institution both in the short run and long run.

This paper concludes that in order to approach integrative curriculum development in institutions of higher education several factors should be taken into careful considerations: Culture of curriculum development (university culture can be rigid and less receptive to external feedback and input and thus may not permit a look 
at other variables thus not allowing a comprehensive approach); lack of strategic planning (education strategic management); limitation of resources (financial, human expertise); leadership does not take it seriously and strategically; and, no competition and lack of exigency from the beneficiaries (students, parents and industry). Therefore, it is suggested that in order to have an integrative approach to develop, implement and evaluate curriculum, educational institutions should consider existing theories and principles for designing new or restructuring existing curriculum more appropriately. It is recommended that a democratic process of curriculum development be introduced, which make provisions for all the role players to participate (Hayward, 2000).

It is ideal to have an integrative approach to curriculum development by institutions of higher education. However, there are common implications and challenges in this approach: the need for changes in curriculum is constant and rapid since the work and social environment is changing and dynamic; there are differences in the learning styles of individual students as well as differences in teaching styles, so finding the best match between the two is not that easy; the culture of educational institutions is a critical factor, given the fact some institutions have centralized management systems and their own traditions of developing curriculum which they believe is already functional. Some educational institutions, especially, in the public sector tend to be bureaucratic, rigid and less receptive to external influences. Also, work process, methods, and other resources such as technology, information management system and management information system are not well advanced; establishing consensus among different stakeholders is time-consuming and almost impossible to establish because of differences in interests and objectives; organizational resources including management time, money, institutional support are limited; and finally, there is a need for dynamic and strategic leadership in order to make sure curriculum development is done appropriately and timely.

\section{Limitations and Future Studies}

This study is based on an extensive literature review that exists in the field of curriculum development. This is a theoretical analysis of diverse issues that concern the current education institutions and educational programs in relation to curriculum development thus providing a theoretical foundation for rigorous and quantitative studies in the future. Research methodologists appreciate the role of literature review based studies in establishing the need for further research while broadening the horizons of the researcher and preventing the researcher from conducting research that already exists (Aitchison, 1998). Literature review helps the researcher and readers to be knowledgeable and understand the research problem better (Leedy, 1989). Furthermore, literature review based studies are also helpful in establishing theoretical grounds for research, identify gabs in the existing knowledge and weaknesses in previous research, discovers connections or other relations between different research results by comparing various investigations (Bless \& Higson-Smith, 2000). Given all those good effects of the outcome of this study, this is a descriptive study involving a type of document analysis and secondary research based on textual information. Some researchers question the validity and reliability of recommendations of such studies since the origin of the information needs scrutiny and critical evaluation. Though this study lays a theoretical justification for designing and delivering an integrative education, however, in order to collect information on ground realities (practices and models) it would be useful to involve interested educational institutions through interviews of professors (one-on-one or in focus groups interviews), administrators, policy makers and industry players alike.

Future studies on curriculum development can be carried out involving interested educational institutions in order to see their practices including designing, implementation and evaluation process of curriculum. Especially, in order to study the gape that exists between the written curriculum and learned curriculum, with a focus on the learning objectives and learning outcomes intended in the curriculum and the actual achievement of these critical ingredients of any curriculum. Interviews of professors, administrators, policy makers, industry players and case analyses of different educational institutions and in different countries can bring about interesting and illuminating information in this regard.

\section{References}

AACSB International. (2012). Eligibility procedures and accreditation standards for business accreditation. Retrieved from http://www.aacsb.edu

Aitchison, J. (1998). Access to books and journal articles by post-graduate students on a course-work master's program in information studies at the University of Natal, Pietermaritzburg (Unpublished MIS Thesis). University of Natal, Pietermaritzburg.

Alberta Education. (2011). Alberta education action agenda 2011-14. Edmonton, AB: Alberta Education. Retrieved from http://education.alberta.ca/media/6432073/actionagenda.pdf 
Alberta Education. (2012). Curriculum development processes, from knowledge to action. Retrieved from http://www.education.alberta.ca/media/6809242/d_chapter1.pdf

Australian Curriculum, Assessment and Reporting Authority. (2010a). The shape of the Australian curriculum, version 2.0. Retrieved from http://www.acara.edu.au/verve/_resources/Shape_of_the_Australian Curriculum.pdf

Baily, J., \& Dangerfield, B. (2000). Applying the distinction between market-oriented and customer-led strategic perspectives to business school strategy. Journal of Education for Business, 75(3), 33-42.

Barnett, R., \& Coate, K. (2005). Engaging the curriculum in higher education. The Society for Research in Higher Education. Maidenhead: Open University Press.

Bless, C., \& Higson-Smith, C. (2000). Fundamentals of social research: An African perspective (3rd ed.). Cape Town: Juta.

Bounds, M. M. (2009). Curriculum content for small business management modules. In L. Cameron, \& J. Dalziel (Eds), Proceedings of the 4th International LAMS Conference 2009: Opening Up Learning Design (pp. 17-27). Sydney, Australia. Retrieved from http://lamsfoundation.org/lams2009sydney/papers.html

Carl, A. E. (2009). Teacher empowerment through curriculum development: Theory into practice (3rd ed.). Juta and Company Ltd., SA.

Cogill, J. (2008). Primary teachers' interactive white board practice across one year: Changes in pedagogy and influencing factors (Unpublished thesis). King's College University of London. Retrieved from http://www.juliecogill.com

Cortes, C. E. (1981). The societal curriculum: Implications for multiethnic educations. In L. Cuban, (1992). Curriculum stability and change. In P. Jackson (Ed.), Handbook of Research on Curriculum. American Educational Research Association.

Cuban, L. (1995). The hidden variable: How organizations influence teacher responses to secondary science curriculum reform. Theory in to Practice, 34(1), 4-11. http://dx.doi.org/10.1080/00405849509543651

David, Fr. R., \& David, Fo. R. (2011). Comparing management curricula with management practices. SAM Advanced Management Journal, 76(3), 48-55.

Dewey, J. (1966). Democracy and education. New York: Macmillan/Free Press (Originally published by Dewey, J. (1918). Democracy and education. The Macmillan Company, New York).

Egan, K. (1979). Educational development. New York: Oxford University Press.

Egan, K. (2003). What is curriculum? Journal of the Canadian Association for Curriculum Studies, 1(1), 9-16.

Evers, E, Rush, J., \& Berdrow, I. (1998). The bases of competence. San Francisco: Jossey-Bass.

Fish, A. (2013). Reshaping the undergraduate business curriculum and scholarship experiences in Australia to support whole-person outcomes. Asian Education and Development Studies, 2(1), 53-69. http://dx.doi.org/10.1108/20463161311297635

González, M. E., Quesada, G., Mueller, J., \& Mueller, R. D. (2011). International business curriculum design: Identifying the voice of the customer using QFD. Journal of International Education in Business, 4(1), 6-29. http://dx.doi.org/10.1108/18363261111170568

Hall, A. (2006). Teaching professional behaviors: Differences in the perceptions of faculty, students, and employers. Journal of Business Ethics, 63, 407-415. http://dx.doi.org/10.1007/s10551-005-2411-6

Hallinger, P., \& Snidvongs, K. (2008). Educating leaders: Is there anything to learn from business management. Educational Management Administration \& Leadership, $36(1), \quad 9-31$. http://dx.doi.org/10.1177/1741143207084058

Hayward, F. M. (2000). Internationalization of US higher education: Preliminary status report 2000. A.C.O. Education.

Hicks, O. (2007). Curriculum in higher education in Australia-Hello? Enhancing higher education, theory and scholarship. Proceedings of the 30th HERDSA Annual Conference.

Huba, M. E., \& Freed, J. E. (2000). Learner-centered assessment on college campuses: Shifting the focus from teaching to learning. Needham Heights, MA: Alleyn and Bacon.

Hyun, E. (2006). Teachable moments: Re-conceptualizing curricula understandings. Studies in the Postmodern 
Theory of Education. New York: Peter Lang.

Hyun, E. (2009). A study of US Academic Deans' involvement in college students' academic success. International Studies in Educational Administration, 37(2), 89-110.

Krull, E., \& Kurm, H. (1996). Hilda Taba-A worldwide known educator from Estonia: Taba's biography, ideas, and impact on Estonian education. Retrieved from www.schulmuseum.at/publikationen/retrospektiven.doc

Leedy, P. (1989). Practical research: Planning and design (4th ed.). New York.

Li, M., Wong, Y. Y., \& Wang, Q. (2005). Management education in the greater China economy: Challenges and task. In I. Alon, \& J. R. McIntyre (Eds.), Business and Management Education in China: Transition, Pedagogy and Training. World Scientific Publishing Co. Pte. Ltd. Singapore.

Longstreet, W. S., \& Shane, H. G. (1993). Curriculum for a new millennium. Boston: Allyn Macmillan.

Mednick, F. (2006). Curriculum theories (Version 1.9). Retrieved from http://cnx.org/content/m13293/latest/

Miller J., \& Seller, W. (1985). Curriculum perspectives and practice. New York: Longman.

Njogu, K. (2012). Conceptualizing the curriculum: Towards a renaissance for theory. American International Journal of Contemporary Research, 2(9).

Null, W. (2011). From theory to practice. Rowman \& Littlefield Publishers, Inc., UK.

Nygaard, C., Hojlt, T., \& Hermansen, M. (2006). Learning-based curriculum development. Retrieved from http//:www.springerlink.com/content/x0071716n4350947/

O'Conner, B. N. (2005). A brief history of the OSRA model curriculum development process: Information technology. Learning and Performance Journal, 1(23), 1-6.

O'Neill, G. (2010). Program design: Overview of curriculum models. Retrieved from http://www.ucd.ie/t4cms/ucdtlp00631.pdf

Ornstein A. C., \& Hunkins, F. P. (2009). Curriculum foundations, principles and issues (5th ed.). Boston: Allyn and Bacon.

Pfeffer, J. (2009). Leadership development in business schools: An agenda for change Stanford University Graduate School of Business Research Paper No. 2016. http://dx.doi.org/10.2139/ssrn.1352622

Quick, P. M., \& Normore, A. H. (2004). Moral leadership in the 21st century: Everyone is watching-especially the students. The Educational Forum, 68(4), 336-347. http://dx.doi.org/10.1080/00131720408984649

Sibley, W. A. (1998). University management 2010: Challenging choices and difficult decisions. New Forums Press Inc., USA.

Taba, H. (1962). Curriculum development-Theory and practice. New York.

The National Center for Education Statistics (NCES) of the U.S. Department of Education. (2002). Retrieved from http://nces.ed.gov/programs/digest/

Tyler, R. W. (1969). Basic principles of curriculum and instruction (2nd ed.). Chicago, IL: University of Chicago Press. http://dx.doi.org/10.7208/chicago/9780226820323.001.0001

Wageman, R. (1997). Critical success factors for creating superb self-managing teams. Organizational Dynamics, 26(1), 49-62. http://dx.doi.org/10.1016/S0090-2616(97)90027-9

Webster's College Dictionary. (2010). Random House Kernerman Dictionaries Ltd. Random House, Inc.

\section{Copyrights}

Copyright for this article is retained by the author(s), with first publication rights granted to the journal.

This is an open-access article distributed under the terms and conditions of the Creative Commons Attribution license (http://creativecommons.org/licenses/by/3.0/). 